\title{
Systemic coordination and the problem of seasonal harmful algal blooms in Lake Erie
}

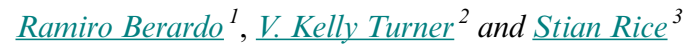

\begin{abstract}
The management of natural resources may potentially be improved when governance structures in social-ecological systems enable coordination among multiple actors who may operate on the same or different geographic and/or governmental scales. In this article, we analyze the network of formal coordination ties that link governmental and nongovernmental actors in the Maumee River watershed, which is the largest source of phosphorus loading into Lake Erie, one of the five Laurentian Great Lakes of North America. Since the 1990s, Lake Erie has seen a return of the seasonal harmful algal blooms (HAB) that were common in the 1960s and 1970s, and considerable research suggests that they might be triggered by excessive amounts of phosphorus produced by agriculture. Analyzing an assortment of documents that collectively detail how stakeholders relate to each other on the topic of nutrient management in the watershed, we examine who are the actors that are more likely to fulfill coordination roles, and the scales at which coordination takes place (vertically vs horizontally). Results suggest that coordination has been formalized vertically, with actors who operate at higher governmental levels being more likely to coordinate the activities of actors at lower levels. In addition, we see evidence of horizontal coordination but only in the confines of the individual state jurisdictions that share the watershed. We see this as a potentially important obstacle to solving the HABs problem in Lake Erie, given that the management of interjurisdictional watersheds is likely to be ineffective in the absence of proper coordination across the different jurisdictions that share the watershed.
\end{abstract}

Key Words: coordination; harmful algal blooms; Lake Erie; nutrient management

\section{INTRODUCTION}

The sustainable use of natural resources in social-ecological systems is a complicated goal to achieve because multiple actors often have radically different views about management goals. Evidence suggests that actors can achieve their sustainable management goals by reaching agreements that can be monitored and properly enforced, either formally or informally (Ostrom 1990). In some situations, these agreements need to be achieved rapidly, as when transient environmental problems require the quick mobilization of collaborative networks to tackle a systemic environmental problem (Berardo et al. 2015, Bodin 2017).

Absent this type of collective action, the likelihood of overexploitation or misuse of resources grows rapidly (Ostrom 1990, Berardo 2014), a problem that can be exacerbated particularly when multiple levels of government are involved in management actions (Guerrero et al. 2015, Berdej and Armitage 2016, Ekstrom and Crona 2017). The resulting lack of fit between ecosystems and governing institutions may be a leading cause of significant environmental degradation in social-ecological systems across the planet (Folke et al. 2007).

In such situations, the management of natural resources may be improved when governance structures enable coordination among multiple governmental and nongovernmental actors who may operate on the same or different geographic and/or governmental scales. Coordination is one of the central components of collaborative governance because it entails bringing together actors whose individual agendas may, in occasions, be in complete opposition to each other (Berardo and Scholz 2010, Bodin et al. 2017). Examining how coordination happens, what shapes it and what forms it adopts, can generate insights for enhancing institutional fit because different coordination structures may be more or less appropriate for addressing the problems actors face in social-ecological systems.

In this article, we analyze the network of formal coordination ties that link governmental and nongovernmental actors in the Maumee River watershed, which is the largest source of phosphorus loading into Lake Erie, one of the five Laurentian Great Lakes of North America. Since the 1990s, Lake Erie has seen a return of the seasonal harmful algal blooms (HAB) that were common before the passage of the United States Clean Water Act in 1972, a problem that many academic researchers link to intensive farming and the use of excess fertilizer in the Maumee River watershed (Obenour et al. 2014, Scavia et al. 2014, Kerr et al. 2016, Scavia et al. 2016).

Although coordination is usually measured by observing networks of informal interactions (Berardo and Scholz 2010), coordination can also be formally prescribed via textual sources that organize actor relations (Olivier 2017), as when a written policy document mandates how certain local governmental agencies need to report activities to a higher level authority. Here, we examine what we term the "formal coordination network of the Maumee River watershed," which is shaped by an assortment of documents that collectively detail how stakeholders relate to each other on the topic of nutrient management in the watershed. We explore what sort of actors are more likely to fulfill coordination roles, and the geographic and governmental scales at which coordination takes place. Specifically, we examine the extent to which formal coordination is structured: (1) vertically (across jurisdictional levels) versus horizontally (both along jurisdictional and geographic levels) and (2) as a directed relationship in which one actor coordinates the activities of another one versus an undirected one in which actors can coordinate each other.

${ }^{1}$ School of Environment and Natural Resources. The Ohio State University, ${ }^{2}$ Urban Planning Department, Luskin School of Public Affairs, University of California Los Angeles, ${ }^{3}$ Center for Urban Environmental Research and Education, University of Maryland, Baltimore County 
Our goal in this article is not to test specific theories of coordination, but rather to provide a detailed description of how mandated formal coordination is structured in the watershed. The analysis of the formal ties among stakeholders will illuminate potential and limitations of the current institutional architecture in the watershed, and thus may help us improve our understanding of how governmental and nongovernmental stakeholders can contribute to improving water quality in Lake Erie.

\section{COORDINATION AND INSTITUTIONAL FIT IN COMPLEX GOVERNANCE SYSTEMS}

In social-ecological systems with complex polycentric governance structures, coordination is key to achieve the sustainability of both collaboration efforts and use of common-pool resources (Galaz et al. 2012, Berardo and Lubell 2016). Coordination, in these cases, is the process of bringing together actors that participate in governance systems in order to improve their capacity to learn about and address the problems they face (social, political, and environmental). Coordination promotes learning through information sharing (Cohen et al. 2012) and, ultimately, enables collaborative and adaptive governance processes thought to facilitate the solution to environmental problems (Huntjens et al. 2012, Wyborn 2015). Higher levels of coordination can also correlate with lowering transaction costs; as stakeholders come together and establish stable relationships, the information costs of developing mutually advantageous agreements, negotiation costs of distributing the gains of collaboration, and enforcement costs of minimizing the risk of mutual defection can drop in the long term (Lubell et al. 2017). Governance systems where transaction costs are lower can in turn facilitate collaborative behavior, making the system more flexible and responsive to rapid environmental change (Berardo and Lubell 2019). Summing up, higher levels of coordination lead to improved social-ecological fit because actors are more likely to quickly learn about problems and adapt accordingly (Ekstrom and Crona 2017).

Scholars interested in the study of coordination in complex governance systems have generally framed coordination as a vertical or horizontal phenomenon. As a top-down process, coordination is facilitated by either an actor, organization, or an institution that brokers relationships between others located at lower jurisdictional levels (Berardo and Scholz 2010, McAllister et al. 2015). Examples abound. In their study of the Solomon Islands Locally Managed Marine Area Network (SILMMA), for instance, Cohen et al. (2012) argue that centralized governance network structures may facilitate coordination because a strong central actor is more likely to have the much needed resources that can trigger sustained collaboration at a systemic level. Gerlak (2004), in turn, studies the institutional structure to manage the Danube River basin, and concludes that coordination can be improved by transferring power to larger institutional regional frameworks that can bring national and subnational level actors together. Alexander et al. (2017) also claim that vertical crosslevel coordination can be more attractive than horizontal coordination, particularly when different sites are strongly and densely connected from an ecological standpoint. They describe management actions to counteract the establishment of invasive Indo-Pacific lionfish (Pterois volitans and Pterois miles) across marine protected areas (MPAs) in Jamaica and show that because the MPAs were interconnected ecologically, horizontal coordination involving MPA managers could have been costly. As a result, vertical coordination became more attractive, with local managers connecting to higher level authorities that coordinated their responses to the problem.

Other research shows that coordination that takes place horizontally across geographic and jurisdictional boundaries can be crucial to solve environmental problems (Berdej and Armitage 2016), particularly when these problems manifest themselves as systemic crises that demand quick political attention. Boin (2009), for example, argues that decisions in the presence of pivotal crises emerge from various alternative loci of decision making and coordination, instead of central decision makers. The main argument is that polities often respond to crises through emerging networks in which multiple organizations that are usually disconnected come together to coordinate their behavior, an idea that has been espoused by others who see decision making as the product of interactions in "ecologies of policy games" that are not centrally structured (Lubell 2013, Berardo and Lubell 2016, Lubell et al. 2017). It is the "lateral" or horizontal coordination that takes place in these polycentric response networks that gives actors a better shot at coping with the inherent risk that accompanies widespread environmental crises (Boin and Hart 2003).

Horizontal coordination can take place across both jurisdictional and geographic boundaries (Pressey and Bottrill 2009, Pelosi et al. 2010). Jurisdictional fragmentation is one of the main challenges for the management of resources that spread across political and administrative boundaries (Feiock and Scholz 2009). Thus, governance systems should be more successful at solving environmental problems when actors work with others on their same jurisdictional levels to coordinate their behaviors and positions. This horizontal coordination across jurisdictions of the same level should be even more marked at the subnational level (state, province, county, or local levels, or their idiosyncratic equivalents) because it is often the case that local actors are in a better position to fully understand the causes of environmental problems (Ernstson et al. 2010, Kininmonth et al. 2015).

In addition to the need to accomplish horizontal coordination at the jurisdictional level, there is considerable research in socialecological systems scholarship showing that coordination should ideally involve actors who operate mostly inside the boundaries of the ecological system that is under duress (Adger et al. 2005, Ostrom 2010, Guerrero et al. 2015, Kininmonth et al. 2015). For instance, in the case of the management of water resources, it is often argued that regulations and management actions should be designed at the level of the watershed, which very rarely overlaps with political-administrative boundaries (Sabatier et al. 2005, Lubell and Fulton 2008, Mandarano and Paulsen 2011, Hoornbeek et al. 2013). According to this line of thinking, socialecological systems with high institutional fitness should exhibit higher levels of coordination at the geographic scale in which environmental problems occur.

Finally, some research focuses on the type of coordination tie that can be created between actors. Although coordination (particularly vertical coordination) can sometimes be thought of as a directed relationship, with one party at a higher level coordinating the activities of another at a lower level, in many instances coordination requires actors to engage in an undirected, 
i.e., reciprocal, relationship. In other words, policy actors in a governance system often need to learn from each other and change or adapt their behaviors based on what others want; in such cases, coordination involves two parties working in concert to achieve a common goal. Reciprocity in interactions engenders trust and signals commitment to working jointly in shared problems (Berardo and Scholz 2010, Berardo 2014), and thus a socialecological system vested with a high level of institutional fit should exhibit a higher level of reciprocity in coordination ties.

These manifestations of coordination relationships (vertical, horizontal, and reciprocal) are not mutually exclusive. In a socialecological system with good institutional fit, environmental problems should be easier to solve (or adapt to) when the multiple manifestations of coordination coexist. Below we examine whether this is the case by studying coordination ties in the Maumee River watershed, the main source of nutrient loading into Lake Erie.

\section{THE MAUMEE RIVER WATERSHED}

The Maumee River watershed drains into Lake Erie, which is the southernmost, shallowest, warmest, and smallest by volume of all five North American Great Lakes, and the source of potable water for approximately 11 million residents in both Canada and the United states (U.S. EPA 2015). The Western Basin of Lake Erie where HABs tend to occur has an average depth of less than eight meters and a history of water quality problems starting in the mid-20th century. In 1972, the U.S. Congress passed the Clean Water Act (CWA) and the governments of Canada and the United States signed the Great Lakes Water Quality Agreement (GLWQA). ${ }^{[1]}$ Collectively, these policy responses improved water quality by targeting point source pollution (Jetoo et al. 2015) and as a result, annual algal blooms receded.

However, in the mid-1990s, algal blooms returned to Lake Erie as loadings of dissolved phosphorus (DP) began to increase. Since then, HABs have appeared every year almost with clockwork regularity, with some of the worse HABs on record occurring in the last decade. The severity of some of these HABs has posed significant public health problems, in addition to problems for local economies such as HABs negatively affecting tourism and water treatment plant operations (Ohio Travel Association 2015). In August of 2014, for instance, the City of Toledo in northern Ohio (which draws drinking water for its population of approximately 400,000 residents from Lake Erie) issued a "do not drink" advisory for tap water as toxin concentrations of cyanobacteria, colloquially referred to as "blue-green algae," reached very high levels.

The reappearance of HABs in Lake Erie has been mostly attributed to excessive phosphorus loading from agriculture in the Maumee River watershed (Obenour et al. 2014, Scavia et al. 2014, Kerr et al. 2016, Scavia et al. 2016), which covers portions of Indiana, Michigan, and Ohio and drains approximately 21,000 $\mathrm{km}^{2}$ of fertile agricultural land where intensive agriculture is practiced (Fig. 1).

The problem is not easy to fix. In addition to the technical difficulties of pinpointing the source of nutrients (there are over 18,000 farms in the watershed), there are other variables that negatively affect the likelihood of finding quick solutions to the problem. For example, the historically low level of interstate coordination to jointly address the issue of water quality in the watershed may have been exacerbated by a persistent trend toward decentralization in the U.S. since the 1970s that undermined the potential for governance at the ecosystem level in the Great Lakes basin (Botts and Muldoon 2005, Jetoo et al. 2015).

Fig. 1. The Maumee River watershed.

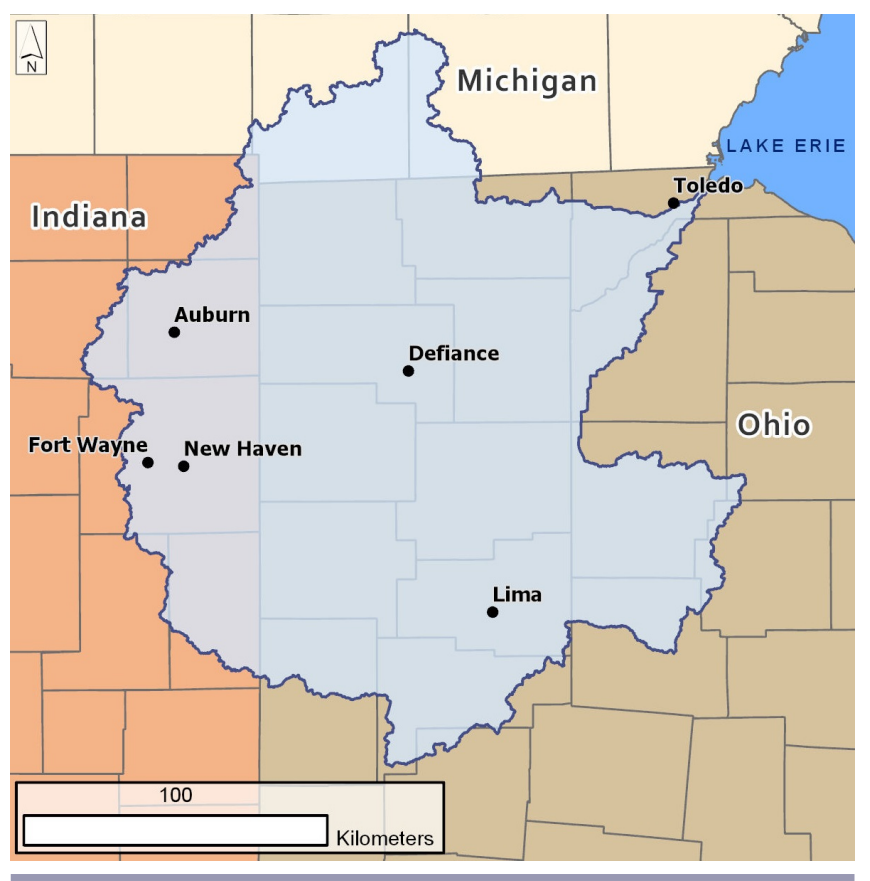

Yet there are also ongoing efforts to address the problem that, if successful, have the potential to contribute to the sustained improvement of water quality in the watershed. The GLWQA, for instance, was amended in 2012 to establish new nutrient management goals for each of the Great Lakes. One of the mutually agreed upon key commitments in the agreement is that, by 2016, binational objectives for phosphorus concentrations, loading targets, and loading allocations had to be determined to address HABs in the western basin of Lake Erie. As a result, representatives of both Canada and the U.S. officially approved phosphorus loading targets in February of 2016. The targets were set to reduce phosphorus loadings by $40 \%$ (using 2008 loading amounts as the baseline). A second key commitment was to develop binational phosphorus reduction strategies and Domestic Action Plans (DAPs) to achieve the targets by 2018 . These plans are currently under development.

There are also efforts to coordinate policy responses at the subnational level. Perhaps the most important of these is the agreement signed by Michigan, Ohio, and the province of Ontario in June of 2015 to also reduce phosphorus loads to Lake Erie by $40 \%$ by 2025 . Setting a deadline is valuable, but, perhaps, undercut by the fact that each of the signatories are given wide latitude to develop individual plans to achieve the goal, with no penalties if they fail to reach the $40 \%$ target. This agreement illustrates how a coordinated response to phosphorus reduction is potentially vulnerable to free-riding by individual states, absent institutional triggers to punish agreement-shirking behavior. 
Other initiatives involve governmental and nongovernmental actors at multiple levels. For example, the tri-state western Lake Erie Basin (WLEB) Phosphorous Reduction Initiative ("the initiative") involves representatives of the three states, plus federal and local agencies. The initiative is a five-year program spearheaded by the Natural Resource Conservation Service (NRCS, part of the federal Unites States Department of Agriculture), which is designed to provide technical and financial assistance to landowners to improve water quality and protect soil health, among other objectives.

\section{DATA COLLECTION}

To assess what types of formal coordination ties predominate in the Maumee River watershed, we first collected data to examine the activities of organizations with managing authority that perform nutrient management functions within the Maumee watershed. These organizations may be public or private, and include governmental agencies, corporations, or nongovernmental organizations that have an established mission (or vision) to explicitly deal with the topic of nutrient (phosphorus) runoff and/ or transport via surface water. Examples are the U.S. Department of Agriculture, the Michigan Department of Environmental Quality (a state agency), the Ohio Farm Bureau (a grassroots level organization that assists farmers), the Blanchard River Watershed Partnership, etc. An initial list of organizations was identified using the Ohio Watershed Network (https://ohiowatersheds.osu. edu/home) and Adopt Your Watershed (U.S. EPA 2016) and expanded through subsequent document analysis until no new organizations were identified. ${ }^{[2]}$

The next step was to code public documents (including legislative documents, web sites, prospectuses, annual reports, marketing materials, newsletters, and articles of incorporation) to build our "coordination matrix." ${ }^{3]}$ This matrix has cells $x_{i j}$ with values of 1 when actor $i$ coordinates the activities of (or fulfills a coordination role for), actor $j$ in regards to the topic of nutrient management in the Maumee River watershed. For instance, actor $i$ may have a specific mandate (through a published mission statement) to "facilitate communication," "introduce," "involve," or "encourage participation" of actor $j$. If that is the case, our network would show a directed tie originating in actor $i$ and landing on actor $j$. All coded documents were published between July of 2014 and January of 2016.

In some cases, actor $i$ may fulfill a coordination role for actor $j$ while $j$ fulfills a simultaneous coordination role for $i$. In such instances, our network would show an undirected tie between actors $i$ and $j$. For example, the Great Lakes Commission (GLC, actor \#24 in Fig. 2) and the National Resources Conservation Service (NRCS, part of the U.S. Department of Agriculture and actor \#54) provide mutual coordination support. Under the GLC's Strategic Plan, the Commission performs "policy coordination and advocacy" to help partner states and subnational organizations "speak with a common voice" and "advance common interests" (Great Lakes Commission 2017). At the same time, NRCS provides coordination support to GLC for GLC-initiated or funded regional programs, like the Great Lakes Restoration Initiative (GLRI).

There are 120 actors and 118 ties in the network, which results in a low level of density (0.01) and an intermediate level of outdegree centralization (0.17). Figure 2, created with Gephi (Bastian, Heymann, and Jacomy, 2009, unpublished), contains the graphical depiction of the network. In the figure, the size of the nodes reflects their out-degree, or "outgoing coordination ties." Isolates nodes with no ties have been removed to improve readability. A quick overview shows that the network is characterized by geographic assortativity, with nodes mostly linking to others based on which state they are active on, particularly in Indiana and Ohio. The "other" category comprises actors who do not operate exclusively inside the geographic limits of the three states that share the Maumee watershed, e.g., federal agencies and organizations with a national reach. The most active node in the network is the Natural Resources Conservation Service (node \#54), an expected result given that organization's central mandate to promote programs among farmers to improve soil health and water quality. The full names of each node depicted in the figure are available in Table A1.1 in Appendix 1.

Fig. 2. Coordination network in the Maumee River watershed.

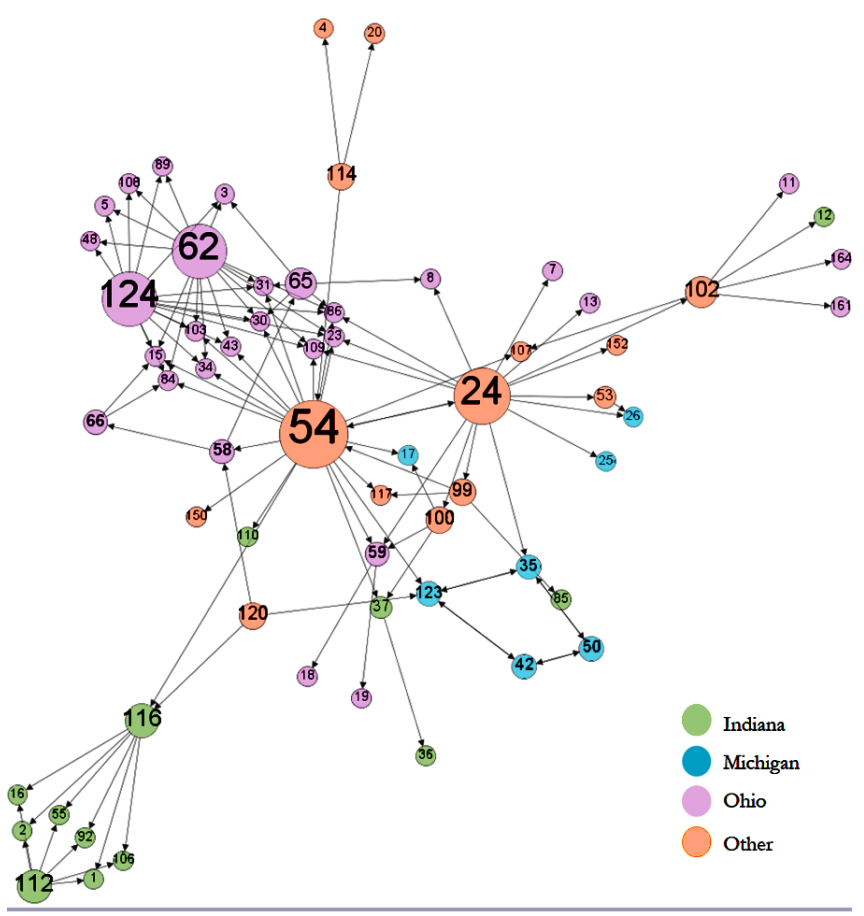

Erratum: Figure 2 was originally published without a legend. The omission was corrected on 9 September 2019

\section{MODELING STRATEGY}

To discern what are the dominant patterns of coordination in the network, we estimated an exponential random graph model (ERGM) using the package "ergm" in R (Hunter et al. 2008, Handcock et al. 2019). ERGMs view observed network ties as a possible realization of a stochastic network process (Robins et al. 2007, Robins 2011, Robins and Lusher 2013), and can be built to estimate the drivers of activity in a network, including both endogenous effects (where the presence of ties depends on the presence of other ties) and exogenous effects (where attributes of nodes explain the ties). Substantively, nodes in networks form configurations of relationships when they interact with other 
nodes and these configurations have parameters attached to them that represent just how likely they are given all the other configurations included in the model. Hence, a positive and significant parameter coefficient will indicate that the configuration associated with that parameter occurs at a higher frequency in the observed network than in comparison networks where links are generated randomly. ${ }^{[4]}$

To examine whether vertical coordination drives activity in the network, we used a set of three dummy variables that capture the jurisdictional level at which the actors operate: federal level (value of 1 for organizations that operate at the federal level and 0 otherwise), state level (1 for organizations that operate at the state level and 0 otherwise), and substate level (1 for organizations that operate either at a level lower than state and 0 otherwise). We included a simple "outdegree" effect (see Fig. 3) for each of the first two variables, leaving the last out of the model as a baseline comparison.

Fig. 3. Coordination tie based on attribute.

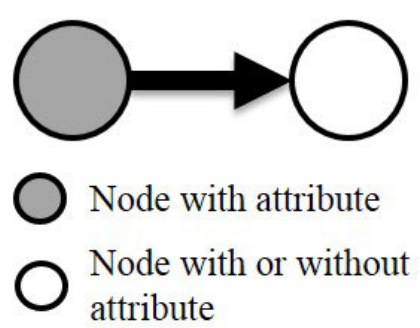

Evidence for the predominance of vertical coordination would result if actors operating at higher levels were more active in the coordination network than those operating at the lower levels (federal $>$ state $>$ substate). We thus would expect the two coefficients to be positive and significant, with the size of the coefficient for the federal level variable being greater in magnitude than the coefficient for state level.

To test for the presence of jurisdictional horizontal coordination we used the same three dummy variables as described in the previous paragraph (again, excluding substate level from the model as a comparison category), but this time included a "node attribute match" effect for each of them, as illustrated in Figure 4.

Fig. 4. Coordination tie based on matched attribute.

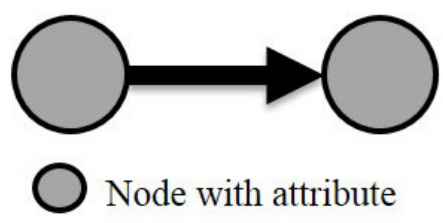

Evidence of jurisdictional horizontal coordination would be indicated by a negative effect for the variable federal level, and a nonsignificant effect for the variable state level, which would mean that coordination happens mostly at the subnational level, i.e., horizontally. Additionally, we also included matched attribute effects for three dummy variables that measure in which state (Indiana, Ohio, or Michigan) the organization is based. A fourth dummy variable, for actors who are based elsewhere, was left out of the model as a comparison category. We would expect to see three positive coefficients, indicating that coordination happens mostly within the confines of separate state jurisdictions.

As we mentioned before, coordination can happen at a horizontal level, but based on geographic, rather than jurisdictional attributes. To test whether this was the case or not, we used a dummy variable that captures whether the actor operates mostly inside the Maumee River watershed boundaries (value of 1), or beyond these boundaries ( 0 ). A positive and significant coefficient for this variable would show evidence of horizontal coordination based on geographic factors.

Finally, to test whether coordination ties tend to be reciprocal or not, we included an endogenous effect in the model for reciprocity, which captures whether a tie from actor $i$ to $j$ is more likely to exist given that a tie exists from actor $j$ to $i$ (see Fig. 5).

Fig. 5. Coordination tie based on reciprocity.

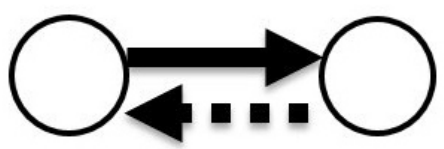

\section{Controls}

Our model incorporated a number of control variables to account for higher levels of activity (outgoing degree ties) in the network. We included four dummy variables that capture whether organizations work on four types of best management practices (BMPs) that have been deemed as critical by farmers to improve water quality in the Maumee River watershed (Wilson et al. 2013). We call the first of these variables Nutrient Application, which identifies whether an actor's activities are directed toward promoting best practices for nutrient application (1) or not (0). These include soil testing, grid sampling, nutrient management planning, and the use of crop consultants. The second dummy variable is Soil Health, which identifies whether an actor's activities focus on promoting soil health management strategies (again, with values of 1 for those that do, and 0 for those that do not). Soil health practices include tillage practices, crop selection, and the use of cover crops. The variable Water Filtration measures whether an actor works on water filtration management strategies (1) or not (0). These include practices such as the use of grass waterways and filter strips. Finally, Manure Management adopts a value of 1 for actors whose activities include promoting manure management strategies, and 0 otherwise. A positive effect for all these variables would indicate that actors who promote best management practices are also more likely to coordinate the actions of other actors. We believed this would indicate a stronger social-ecological fit in the Maumee River watershed, given that the most serious threat to water quality in Lake Erie comes from agricultural activities in watershed.

We also controlled for the capacity of actors to test and/or monitor water quality as an operational function (Monitoring Role). Water quality testing and monitoring may involve a range 
of activities, from conducting one-off site tests to evaluating the effectiveness of a BMP, to the regular recording of test results over a long period of time from several monitoring stations along a river. Actors that assume this role have a score of 1 in this variable, and 0 otherwise. In a system with high levels of socialecological fit, we would expect the coefficient associated with this variable to be positive, signaling that actors with the capacity to monitor resources are more active in coordinating the behavior of other stakeholders.

Finally, we included four endogenous effects that collectively account for network activity that is dependent on the presence of other ties in the network (in other words, activity that is independent of nodal attributes). The geometrically weighted edgewise shared partners (Gwesp) effect was used to model closure in the network through the existence of triangles, i.e., the likelihood that a tie between two actors exists given that they share common partners. The effect was accompanied by a decay parameter to discount the effect of extra shared partners, which we fixed at 0.5 (for more information about the decay parameter, see Hunter and Handcock 2006). The geometrically weighted indegree distribution (Gwidegree) was included to model in-degree activity (the reception of coordination ties). A decay parameter was also used, and fixed at 1 . A third term that we added to the model was Isolates. The effect accounts for the presence of nodes with no ties to other nodes in the network, i.e., those that are not the initiator or the recipient of a tie. Finally, the Edge parameter simply accounted for the formation of ties independently of other configurations or nodal attributes that have been described up to this point. The value of the coefficient represents exactly the density of the network in log-odds.

\section{RESULTS}

Table 1 presents the results of the estimation of the model, which converged properly with $t$ values smaller than 0.1 for all the coefficients (indicators of model goodness of fit are contained in Appendix 1). Coefficients can be interpreted as conditional log odds, and thus they represent the likelihood to observe the formation of the particular network configuration to which they are attached, given all other configurations represented in the model.

In general, the results show that vertical coordination across jurisdictional levels and horizontal coordination in the same jurisdictional levels drives activity in the network. The coefficients for the outdegree of actors operating at the federal and state level are positive and statistically significant at the 0.01 level, indicating that actors operating in those levels have more outgoing coordination ties than actors operating at the local level. Furthermore, the coefficient for federal actors is higher in magnitude than for state actors, which further reinforces the finding that formal vertical coordination is present in the Maumee watershed. These results are valuable to illustrate that, particularly in complex governance systems where resources are located across multiple jurisdictional levels, higher level actors can contribute to reduce the potential for regulatory and managerial fragmentation by adopting a more active role in coordinating the behavior of actors in lower levels.

Regarding horizontal coordination ties across jurisdictions, our results did not meet our expectations. We expected to see negative coefficients for the nodematch effect for actors operating at the federal level, and nonsignificant effects for the actors operating

Table 1. ERGM model parameter estimates. BMP, best management practices.

\begin{tabular}{lc}
\hline \hline & Coefficients (St. error) \\
\hline Vertical Coordination & \\
Federal Level (outdegree) & $2.842^{*}(0.339)$ \\
State Level (outdegree) & $1.708^{*}(0.309)$ \\
Baseline: Sub-state level & \\
& \\
Horizontal Coordination & \\
Jurisdictional & $0.112(0.289)$ \\
Federal Level (nodematch) & $-0.355(0.234)$ \\
State Level (nodematch) & \\
Baseline: Substate level & $1.508^{*}(0.339)$ \\
& $1.569^{*}(0.270)$ \\
Indiana based (nodematch) & $0.797^{*}(0.286)$ \\
Ohio based (nodematch) & \\
Michigan based (nodematch) & \\
Baseline: based elsewhere & $-0.240(0.395)$ \\
Geographic & \\
Actor operating inside watershed boundaries & $0.883(0.496)$ \\
& \\
Reciprocity in Coordination & \\
Areas of Action & $2.725^{*}(0.707)$ \\
BMP Nutrient Application (outdegree) & $-0.433(0.876)$ \\
BMP Soil Health (outdegree) & $-0.716(0.651)$ \\
BMP Water Filtration (outdegree) & $-1.689^{*}(0.416)$ \\
BMP Manure (outdegree) & $-0.239(0.209)$ \\
& \\
Monitoring Role (outdegree) & $-0.193(0.284)$ \\
Other endogenous effects & $0.142(0.609)$ \\
Gwesp (decay = 0.5) & $-8.093^{*}(0.426)$ \\
Gwidegree (decay = 1) & 1038 \\
Isolates & \\
Edges & \\
Akaike Inf. Crit. & \\
Bayesian Inf. Crit. & \\
\hline Note: *p < 0.01 & \\
\hline & \\
& \\
& \\
& \\
& \\
& \\
& \\
& \\
&
\end{tabular}

at the state level, which together would have indicated that coordination activity can be described as an assortative process that occurs mostly along jurisdictions at the subnational levels. But our results show a more nuanced pattern. The coefficient for the federal Level nodematch effect is not significantly different than the baseline category (actors operating at the substate level), while the state level actors do not show a higher or lower likelihood of having coordination ties with other actors at their levels, when compared to the baseline category. These results can be coupled with those reported in the previous paragraph to infer that the majority of coordination ties in this system "flow downward" toward actors that operate in the lower level, rather than horizontally to other actors in their same level. This may be at least partially explained by the fact that state-level actors in the Maumee River watershed are based in three different states, and that actors operating in one state are unlikely to be able to exert considerable influence on actors in another one. The Ohio Environmental Protection Agency, for example, cannot coordinate the activities of the Michigan Department of Environmental Quality (at least not with regard to actions that affect the likelihood of HABs in Lake Erie). 
In line with this observation, the following set of coefficients in Table 1 provide additional evidence that horizontal coordination tends to be (mostly) confined inside state boundaries. The nodematch effects for the three dummy variables that capture the state in which the actors operate (Indiana, Michigan, and Ohio) are positive and statistically significant at the 0.01 level, indicating that actors in each state are more likely to establish coordination ties to other actors in the same state (in comparison to the baseline category of actors who do not operate mainly inside any of the states that share the watershed). This is not an unexpected result because the American federal system is built on the powerful administrative and political powers vested on state governments. Each of the states that share the watershed, for instance, has wellstaffed agencies whose formal purpose is to protect (and regulate the use of) natural resources in their states, and it is common for state-level bureaucracies to operate without coordinating with each other.

Results do not indicate the presence of horizontal coordination ties based on geographic factors. The coefficient for the outdegree effect of actors that operate inside the boundaries of the Maumee River watershed (e.g. St. Joseph River Watershed Initiative, Friends of Cedar Creek, etc.) is not statistically different from zero. This means that these actors are not more likely to engage in coordination activities when compared to others that operate beyond the confines of individual watersheds.

Finally, results do not show reciprocity in coordination ties. The coefficient for this effect is positive but not statistically significant at least at the 0.05 level. This result indicates that coordination in the Maumee River watershed (at least the formal coordination ties that are described in the documents we analyzed) is mostly the product of directed relationships involving a party that coordinates and another that is coordinated. In some cases, actors do in fact have reciprocal coordination ties, which are thought to improve learning among stakeholders and contribute to the solidification of collaborative reputations (Berardo and Scholz, 2010). But the frequency at which those reciprocal relationships are formalized in the network is not high, given the total number of ties that exist in it.

With regard to the control variables we included in the model, results show that actors whose activities focus on promoting best management practices on the topic of nutrient applications are more likely to adopt a coordinating position than actors who do not engage in these activities. But we found that engaging in activities in other best management practices does not explain coordinating activity. In fact, in one of the variables (BMP Manure), the effect is negative and highly significant, indicating that actors who engage in the promotion of best management practices to reduce the noxious effect of excessive manure applications on fields as fertilizer are in fact less likely to coordinate the behavior of other actors in the watershed. The final set of four coefficients in the model account for endogenous effects in the formation of ties. Two of these coefficients are statistically significant at the 0.01 level. The positive coefficient for isolates simply reflects that there is a significant number of actors in the network who are not connected to other nodes by coordination ties (either outgoing or incoming). The edge parameter is akin to the constant in standard regression approaches (Cranmer and Desmarais 2011). Its negative value reflects the extremely low density in the network, and indicates that nodes have a very low likelihood of forming ties that are independent of the processes captured by other effects in the model.

\section{DISCUSSION}

Overall, our results illustrate the challenges of coordinating the behavior of multiple actors in complex social-ecological systems where natural resources are managed in jurisdictionally fragmented landscapes. Research focusing on the drivers of institutional fit in social-ecological systems argue that coordination has a key role to play in facilitating learning, increasing social capital, and contributing to the overall sustainability of collaborative interactions that are necessary to solve collective action dilemmas. Thus social-ecological systems where both horizontal and vertical coordination takes place are more likely to succeed in finding solutions to environmental crises.

The results of our analysis in the Maumee River watershed shows that coordination has been formalized vertically, with organizational actors that operate at higher levels being more likely to adopt a coordination role. Linking higher level authorities to local level resource users is important to prevent the overuse of common-pool resources, and so this result is encouraging insofar as it aligns with findings from previous studies extolling the benefits of vertical coordination (Gerlak 2004, Cohen et al. 2012, Kininmonth et al. 2015, Alexander et al. 2017). In the specific case of the Maumee watershed, previous research has shown that watershed managers cited the importance of higher level authorities in pushing action on politically contentious environmental issues (Rasmussen et al. 2017). Nevertheless, one must keep in mind that the most central actor in the network (the Natural Resources Conservation Service, part of the U.S. Department of Agriculture), in general relies on incentive-based approaches to land conservation that are unlikely to be sufficient to solve the problem of decaying water quality in the Maumee. ${ }^{[5]}$

It is also important to note that systems that rely on top-down coordination may lack formal feedback mechanisms from actors operating at lower geographic scales, which research shows may improve the management actions designed and implemented by higher level actors (Sayles 2018). This is problematic because upward flow of information can help leverage local knowledge about resource systems, improve downward flow of information by revealing how local resource users share information, and generally enhance the design and durability of natural resource management through coproduction processes (Tengö et al. 2014, Salpeteur et al. 2017). Nevertheless, this concern is lessened by previous work in the Maumee watershed showing that lower level actors have contributed to improving phosphorus load models and understanding of the feasibility of different best management practice scenarios to reduce excess nutrient runoff (Kalcic et al. 2016).

Vertical coordination alone is unlikely to generate solutions for system-scale problems, particularly when the social-ecological system of interest crosses multiple subnational jurisdictions. In such cases, cross-scale interactions at the local level are critical to prevent the over or misuse of natural resources (Cudney-Bueno and Basurto 2009). Unfortunately, the evidence of horizontal 
coordination that we find is scant. First of all, actors operating mostly inside the geographic confines of the Maumee watershed are not more likely to fulfill coordination roles. Research has shown that water resources are more likely to be effectively protected when management actions are crafted at the watershed level (Lubell and Fulton 2008, Mandarano and Paulsen 2011, Sayles and Baggio 2017). Thus having actors who operate at the watershed level adopt leading coordination roles would probably contribute toward the goal of devising better responses to the water problems in the Maumee watershed, which are fundamentally local. Yet there is no evidence in our results that actors operating mostly inside the Maumee watershed are more likely to adopt a coordination role.

What we see instead is that the dyadic coordination relationships that take place at a horizontal level tend to occur inside jurisdictional boundaries, with coordination ties mostly joining actors within the same states. This could be seen as a potential obstacle to solving the HABs problem in Lake Erie; water policy and management studies have shown that the management of interjurisdictional watersheds is likely to be ineffective in the absence of proper coordination among the jurisdictions that share them (Sabatier et al. 2005).

A recent example of the lack of coordinated behavior across state lines in Lake Erie was the divergent positions adopted by Michigan and Ohio regarding the declaration of the western basin of Lake Erie (where HABs are usually more noticeable) as "impaired," which would trigger regulatory provisions outlined by the Clean Water Act of 1972. Listing the waters of the western basin of Lake Erie as impaired because of nutrient pollution would prompt the development of regulatory measures to curve the amount of phosphorus allowed to enter the western basin of the lake, thus providing governmental agencies with an enforceable standard to diminish nutrient pollution and improve water quality. Although Michigan declared the western basin as impaired in November 2016, the State of Ohio through its Environmental Protection Agency only declared portions of near shore waters as impaired out of fear that a declaration of impairment beyond these areas could have a negative impact on economic development (Henry 2016). ${ }^{[6]}$ It was only in March of 2018, and under considerable pressure from the U.S. EPA and a lawsuit filed by environmental interest groups, that Ohio's Governor declared Lake Erie impaired. The outcome of both states declaring the waters of western Lake Erie as impaired was not reached through coordination across jurisdictional lines, but rather through independent decision-making processes that were affected by radically different variables. Given that policy innovation at the state level in the U.S. has been shown to be positively affected by interstate learning and coordination (Berry and Berry 1990, Mintrom 1997, Mintrom and Vergari 1998), the lag time between Michigan and Ohio impairment declarations can be seen as an example of the kind of obstacle that may hinder the process of improving water quality in the lake.

Compounding the coordination problem, one must keep in mind that even within state jurisdictional boundaries there might be disagreements among key policy actors that get in the way of solving water quality problems. For instance, in July of 2018, Ohio's Governor issued an Executive Order identifying eight subwatersheds in the Maumee River as "watersheds in distress" that exceeded targets for concentrations of dissolved phosphorous. The Executive Order was sent to the State Director of the Ohio Department of Agriculture (ODA) and the Ohio Soil and Water Conservation Commission (OSWCC) for consent and implementation toward the goal of reducing excessive dissolved phosphorus loads from farms in these subwatersheds. But the OSWCC stalled in granting the consent and the Director of the ODA had to be removed from office in October after siding with farmers who opposed the designation (Ludlow 2018).

Fortunately, some of our findings allow for a more positive outlook. Chief among them is that actors in charge of promoting best management practices in nutrient applications, which include soil testing, nutrient management planning, and the use of crop consultants with specialized knowledge on fertilizer use, are more active in the coordination network, i.e., they coordinate the activities of other members of the network to a greater extent than those who do not promote these BMPs. It is not easy to determine why only this BMP dummy variable achieved significance, but Wilson et al. (2019) show that the one BMP practice in the western Lake Erie Basin that receives the most support among farmers is the application of the right amount of fertilizer based on consistent soil testing. Our finding might simply reflect that actors who are more active as coordinators recognize this preference and make it an important part of their advising portfolios. Zhang et al. (2016) collected data from over 2500 farmers in the Maumee River watershed and found that perceived efficacy of BMPs - the belief that a particular practice will actually reduce phosphorus runoff from farm fields - is positively correlated with adoption of the practices. They suggested as an implication of the work that policies and outreach efforts aimed at increasing farmers' perceived efficacy of practices could lead to higher adoption levels, at least among certain groups of farmers. Finding that actors promoting nutrient application BMPs are in position to reach other stakeholders in the network and engage in a coordinating role makes us hopeful that the outreach efforts referenced by Zhang and colleagues can be more easily accomplished.

There are two main limitations of our work that we would like to acknowledge. The first one is that we have studied coordination ties involving only a relatively small (though critically important) number of actors. Notably, the population of resource users that matters the most to reduce the nutrients that trigger HABs, i.e., farmers, are not included in these documents, and thus they are absent in the network we examine. This is problematic insofar as the "social fit" of responses to problems, i.e., whether they take into account the values, beliefs, and interests of all relevant stakeholders, is as important as their "ecological fit," i.e., whether they align with the spatial and temporal characteristics of biophysical problems (Moss 2012, Epstein et al. 2015). There is significant research on how farmers learn to deal with problems through the adoption of innovative behavior, with one of the main drivers being the possibility to coordinate their behavior with agencies or local networks of farmers or watershed groups (Baumgart-Getz et al. 2012). Moreover, our data set does not encompass private sector crop advisors and farm supply companies that make fertilizer and chemical application recommendations. In order to fully understand the capacity of farmers to contribute to the improvement of water quality in the Maumee watershed, the interactions between farmers, private 
sectors supply companies, public officials, and other actors in the watershed merit further consideration.

The second limitation of our work is that we only focus on the formal ties that are contained in the textual sources we examined. This cross-sectional analysis provides only a snapshot of how coordination ties might be deployed among stakeholders. In real, day-to-day interactions, coordination takes place through a complex set of multiple, overlapping, and iterative formal, semiformal, and informal exchanges that shape and reshape the relationships among actors and their capacity to reach their individual goals (Crona et al. 2017). For instance, actors may come together through joint participation in specific private or public initiatives (e.g., the Great Lakes Restoration Initiative funds thousands of projects across the Great Lakes to tackle a variety of problems, from restoration of polluted areas to prevention of invasive species), planning processes (e.g., locally designed "Nine-Element Nonpoint Source Implementation Strategic Plans" in Ohio), or less formally through joint attendance to meetings and conferences (e.g., the Ohio Sea Grant's annual "Understanding Algal Blooms: State of the Science" conference). Information sharing and learning undoubtedly occur in all of these policy venues, but not in a legally codified way that our data would reflect. More research is needed to fully understand how formal and informal ties collectively affect the capacity of this complex governance system to find coordinated solutions to the severe environmental problems caused by HABs.

\section{CONCLUSION}

Harmful algal blooms in Lake Erie have been a historical occurrence but have become more problematic in recent years, as phosphorus loadings (particularly dissolved reactive phosphorus) has increased as a byproduct of intensive agricultural activities. The Maumee River watershed is the main source of nutrients for the lake, and in this work we have examined the pattern of formal coordination ties that link a large group of stakeholders who have a role to play in the management of water quality in the watershed.

Our results show that formal coordination ties exist, but that they are mostly structured in a way that do not necessarily support, at least theoretically, learning and understanding of the problems at a horizontal level across subnational jurisdictions. This does not imply that solutions to the problem of low water quality in the watershed are impossible to achieve. In fact, there are multiple ongoing efforts to tackle the problem that leverage the expertise of actors to design strategies to reduce phosphorus loading to levels that would contribute to a significant decline in the severity of HABs (Wilson et al. 2019). Yet we believe that these initiatives would be more likely to succeed were they anchored in a formal governance structure in which the vertical coordination that we observed was paired with greater levels of coordination at a watershed scale and a higher level of communication among actors operating in the different states that share the watershed.

Ultimately, decision makers and policy actors with stakes in improving water quality in Lake Erie in general, and the Maumee River watershed in particular, need to create the conditions that make learning about water quality problems, and acting on them, more likely. That starts with the establishment of stable communication ties that can bring stakeholders together, thus lowering the costs of finding coordinated responses to face, and reverse, decaying water quality. Our findings show that more can be done from an institutional standpoint to create such conditions.

[1] The agreement was created by the International Joint Commission (IJC), a binational body formed by representatives of Canada and the United States. The primary goal of the IJC is to foster international cooperation to protect shared water resources. The GLWQA was signed in April 1972, and it was updated in 1978, 1983, 1987, and 2012. The agreement was a successful example of a valuable coordinated response to a critical environmental problem and to this day remains the centerpiece of the institutional architecture to address water quality in the Great Lakes.

[2] The Ohio Watershed Network (https://ohiowatersheds.osu. edu), a service of The Ohio State University Extension, maintains a database of private organizations involved in watershed issues across the state. Adopt Your Watershed (https://catalog.data.gov/ dataset/adopt-your-watershed-29d09), is a service of the U.S. Environmental Protection Agency and "serves as a national inventory of local watershed groups and non-profit organizations involved in protecting water quality" (U.S. EPA 2016).

${ }^{[3]}$ Articles of incorporation are official documents that establish the legal existence of a corporation. These documents are filed with the Secretary of State (or other registrar) for the states in which the corporation conducts business. They are also known as corporate charters or certificates of incorporation.

${ }^{[4]}$ Technically, ERGMs model ties as possibly occurring in the network dependent on the presence of other ties. For instance, a tie between two actors $\mathrm{A}$ and $\mathrm{B}$ that closes a triangle also including actor $\mathrm{C}$ can be assumed to take place when both $\mathrm{A}$ and $\mathrm{B}$ are aware of the presence of the remaining two ties in the would-be triangle (A to $\mathrm{C}$ and $\mathrm{B}$ to $\mathrm{C}$ ). In this sense, ERGMs are ideally suited to examine networks where nodes have full agency. This is not the case with our network because relationships are established formally in policy documents. However, this is less of a concern for us because we are less interested in the endogenous part of the model that in the exogenous part, i.e., how ties are created based on particular attributes of the nodes, rather than the presence of other ties.

${ }^{[5]}$ For example, the two biggest programs financed by the USDA for which the NRCS provides technical assistance are the Conservation Reserve Program and the Environmental Quality Incentives Program. The former is a cost-share program designed to improve land conservation by encouraging farmers to convert cropland to uses that prevent erosion and can positively impact water quality, e.g., cover crops, buffer strips, windbreak trees, etc. The latter provides financial assistance to farmers who adopt conservation practices on agricultural land, including the adoption of nutrient management practices, conservation tillage, etc. Farmer enrollment in both of these programs is completely voluntary.

${ }^{[6]}$ The U.S. Environmental Protection Agency initially supported the Ohio EPA's decision in May of 2016 to avoid the impairment declaration of the whole western basin, but later reversed it in January of 2018 because of procedural reasons. 
Responses to this article can be read online at:

http://www.ecologyandsociety.org/issues/responses. php/11046

\section{Acknowledgments:}

This research was generously funded by the Ohio Sea Grant. We thank Maria Mancilla Garcia, Manuel Fischer, and Orjan Bodin for valuable comments that helped us improve the manuscript. All mistakes remain the authors'.

\section{LITERATURE CITED}

Adger, W. N., T. P. Hughes, C. Folke, S. R. Carpenter, and J. Rockström. 2005. Social-ecological resilience to coastal disasters. Science 309(5737):1036-1039. https://doi.org/10.1126/science.1112122

Alexander, S. M., D. Armitage, P. J. Carrington, and Ö. Bodin. 2017. Examining horizontal and vertical social ties to achieve social-ecological fit in an emerging marine reserve network. Aquatic Conservation: Marine and Freshwater Ecosystems 27 (6):1209-1223. https://doi.org/10.1002/aqc. 2775

Baumgart-Getz, A., L. S. Prokopy, and K. Floress. 2012. Why farmers adopt best management practice in the United States: a meta-analysis of the adoption literature. Journal of Environmental Management 96(1):17-25. https://doi.org/10.1016/j.jenvman.2011.10.006

Berardo, R. 2014. Bridging and bonding capital in two-mode collaboration networks. Policy Studies Journal 42(2):197-225. https://doi.org/10.1111/psj.12056

Berardo, R., and M. Lubell. 2016. Understanding what shapes a polycentric governance system. Public Administration Review 76 (5):738-751. https://doi.org/10.1111/puar.12532

Berardo, R., and M. Lubell. 2019. The ecology of games as a theory of polycentricity: recent advances and future challenges. Policy Studies Journal 47(1):6-26. https://doi.org/10.1111/ psj.12313

Berardo, R., T. Olivier, and A. Lavers. 2015. Focusing events and changes in ecologies of policy games: evidence from the Paraná River Delta. Review of Policy Research 32(4):443-464. https://doi. org/10.1111/ropr.12128

Berardo, R., and J. T. Scholz. 2010. Self-organizing policy networks: risk, partner selection, and cooperation in estuaries. American Journal of Political Science 54(3):632-649. https://doi. org/10.1111/j.1540-5907.2010.00451.x

Berdej, S., and D. Armitage. 2016. Bridging for better conservation fit in Indonesia's coastal-marine systems. Frontiers in Marine Science 3:101. https://doi.org/10.3389/fmars.2016.00101

Berry, F. S., and W. D. Berry. 1990. State lottery adoptions as policy innovations: an event history analysis. American Political Science Review 84(2):395-415. https://doi.org/10.2307/1963526

Bodin, Ö. 2017. Collaborative environmental governance: achieving collective action in social-ecological systems. Science 357(6352):eaan1114. https://doi.org/10.1126/science.aan1114
Bodin, Ö., A. Sandström, and B. Crona. 2017. Collaborative networks for effective ecosystem-based management: a set of working hypotheses. Policy Studies Journal 45(2):289-314. https:// doi.org/10.1111/psj.12146

Boin, A. 2009. The new world of crises and crisis management: implications for policymaking and research. Review of Policy Research 26(4):367-377. https://doi.org/10.1111/j.1541-1338.2009.00389. $\underline{x}$

Boin, A., and P. Hart. 2003. Public leadership in times of crisis: mission impossible? Public Administration Review 63(5):544-553. https://doi.org/10.1111/1540-6210.00318

Botts, L., and P. Muldoon. 2005. Evolution of the Great Lakes water quality agreement. Michigan State University Press, East Lansing, Michigan, USA.

Cohen, P. J., L. S. Evans, and M. Mills. 2012. Social networks supporting governance of coastal ecosystems in Solomon Islands. Conservation Letters 5(5):376-386. https://doi.org/10.1111/ j.1755-263X.2012.00255.X

Cranmer, S. J., and B. A. Desmarais. 2011. Inferential network analysis with exponential random graph models. Political Analysis 19(1):66-86. https://doi.org/10.1093/pan/mpq037

Crona, B., S. Gelcich, and Ö. Bodin. 2017. The importance of interplay between leadership and social capital in shaping outcomes of rights-based fisheries governance. World Development 91:70-83. https://doi.org/10.1016/j.worlddev.2016.10.006

Cudney-Bueno, R., and X. Basurto. 2009. Lack of cross-scale linkages reduces robustness of community-based fisheries management. PLoS ONE 4(7):e6253. https://doi.org/10.1371/ journal.pone.0006253

Ekstrom, J. A., and B. I. Crona. 2017. Institutional misfit and environmental change: a systems approach to address ocean acidification. Science of the Total Environment 576:599-608. https://doi.org/10.1016/j.scitotenv.2016.10.114

Epstein, G., J. Pittman, S. M. Alexander, S. Berdej, T. Dyck, U. Kreitmair, K. J. Rathwell, S. Villamayor-Tomas, J. Vogt, and D. Armitage. 2015. Institutional fit and the sustainability of socialecological systems. Current Opinion in Environmental Sustainability 14:34-40. https://doi.org/10.1016/j.cosust.2015.03.005

Ernstson, H., S. Barthel, E. Andersson, and S. Borgström. 2010. Scale-crossing brokers and network governance of urban ecosystem services: the case of Stockholm. Ecology and Society 15(4):28. https://doi.org/10.5751/ES-03692-150428

Feiock, R. C., and J. T. Scholz. 2009. Self-organizing federalism: collaborative mechanisms to mitigate institutional collective action dilemmas. Cambridge University Press, New York, New York, USA. https://doi.org/10.1017/CBO9780511642319

Folke, C., L. Pritchard Jr, F. Berkes, J. Colding, and U. Svedin. 2007. The problem of fit between ecosystems and institutions: ten years later. Ecology and Society 12(1):30. https://doi.org/10.5751/ ES-02064-120130

Galaz, V., B. Crona, H. Österblom, P. Olsson, and C. Folke. 2012. Polycentric systems and interacting planetary boundaries- 
emerging governance of climate change-ocean acidificationmarine biodiversity. Ecological Economics 81:21-32. https://doi. org/10.1016/j.ecolecon.2011.11.012

Gerlak, A. K. 2004. Strengthening river basin institutions: the global environment facility and the Danube River Basin. Water Resources Research 40(8). https://doi.org/10.1029/2003WR002936

Great Lakes Commission. 2017. Strategic plan for the Great Lakes Commission, 2017-2022. Great Lakes Commission, Ann Arbor, Michigan, USA. [online] URL: https://www.glc.org/wp-content/ uploads/2013/07/GLC-strategic-plan Final Adopted-Jan-13-2017. pdf

Guerrero, A. M., Ö. Bodin, R. R. J. McAllister, and K. A. Wilson. 2015. Achieving social-ecological fit through bottom-up collaborative governance: an empirical investigation. Ecology and Society 20(4):41. https://doi.org/10.5751/ES-08035-200441

Handcock, M. S., D. R. Hunter, C. T. Butts, S. M. Goodreau, P. N. Krivitsky, M. Morris, L. Wang, K. Li, S. Bender-deMoll, and C. Klumb. 2019. ergm: Fit, simulate and diagnose exponentialfamily models for networks. R package version 3.10.4. https:// CRAN.R-project.org/package $=$ ergm

Henry, T. 2016. Michigan declares western Lake Erie waters impaired. The Blade, 10 November. [online] URL: http://www. toledoblade.com/local/2016/11/10/State-of-Michigan-declares-westernLake-Erie-waters-as-impaired.html

Hoornbeek, J., E. Hansen, E. Ringquist, and R. Carlson. 2013. Implementing water pollution policy in the United States: total maximum daily loads and collaborative watershed management. Society \& Natural Resources 26(4):420-436. https://doi. org/10.1080/08941920.2012.700761

Hunter, D. R., and M. S. Handcock. 2006. Inference in curved exponential family models for networks. Journal of Computational and Graphical Statistics 15(3):565-583. https://doi. org/10.1198/106186006X133069

Hunter, D. R., M. S. Handcock, C. T. Butts, S. M. Goodreau, and M. Morris. 2008. ergm: A package to fit, simulate and diagnose exponential-family models for networks. Journal of Statistical Software 24(3):1-29. https://doi.org/10.18637/jss.v024.i03

Huntjens, P., L. Lebel, C. Pahl-Wostl, J. Camkin, R. Schulze, and N. Kranz. 2012. Institutional design propositions for the governance of adaptation to climate change in the water sector. Global Environmental Change 22(1):67-81. https://doi.org/10.1016/ j.gloenvcha.2011.09.015

Jetoo, S., A. Thorn, K. Friedman, S. Gosman, and G. Krantzberg. 2015. Governance and geopolitics as drivers of change in the Great Lakes-St. Lawrence Basin. Journal of Great Lakes Research 41:108-118. https://doi.org/10.1016/j.jglr.2014.11.011

Kalcic, M. M., C. Kirchhoff, N. Bosch, R. Logsdon Muenich, M. Murray, J. G. Gardner, and D. Scavia. 2016. Engaging stakeholders to define feasible and desirable agricultural conservation in western Lake Erie watersheds. Environmental Science \& Technology 50(15):8135-8145. https://doi.org/10.1021/ acs.est.6b01420

Kerr, J. M., J. V. DePinto, D. McGrath, S. P. Sowa, and S. M. Swinton. 2016. Sustainable management of Great Lakes watersheds dominated by agricultural land use. Journal of Great Lakes Research 42(6):1252-1259. https://doi.org/10.1016/j. jglr.2016.10.001

Kininmonth, S., A. Bergsten, and Ö. Bodin. 2015. Closing the collaborative gap: aligning social and ecological connectivity for better management of interconnected wetlands. AMBIO 44 (1):138-148. https://doi.org/10.1007/s13280-014-0605-9

Lubell, M. 2013. Governing institutional complexity: the ecology of games framework. Policy Studies Journal 41(3):537-559. https://doi.org/10.1111/psj.12028

Lubell, M., and A. Fulton. 2008. Local policy networks and agricultural watershed management. Journal of Public Administration Research and Theory 18(4):673-696. https://doi. org/10.1093/jopart/mum031

Lubell, M., J. Mewhirter, R. Berardo, and J. T. Scholz. 2017. Transaction costs and the perceived effectiveness of complex institutional systems. Public Administration Review 77 (5):668-680. https://doi.org/10.1111/puar.12622

Ludlow, R. 2018. Ohio agriculture director fired amid dispute over farms, Lake Erie algae. The Columbus Dispatch, 22 October. [online] URL: https://www.dispatch.com/news/20181022/ohioagriculture-director-fired-amid-dispute-over-farms-lake-erie-algae

Mandarano, L., and K. Paulsen. 2011. Governance capacity in collaborative watershed partnerships: evidence from the Philadelphia region. Journal of Environmental Planning and Management 54(10):1293-1313. https://doi.org/10.1080/09640568.2011 .572694

McAllister, R. R. J., B. M. Taylor, and B. P. Harman. 2015. Partnership networks for urban development: how structure is shaped by risk. Policy Studies Journal 43(3):379-398. https://doi. org/10.1111/psj.12103

Mintrom, M. 1997. Policy entrepreneurs and the diffusion of innovation. American Journal of Political Science 41(3):738-770. https://doi.org/10.2307/2111674

Mintrom, M., and S. Vergari. 1998. Policy networks and innovation diffusion: the case of state education reforms. Journal of Politics 60(1):126-148. https://doi.org/10.2307/2648004

Moss, T. 2012. Spatial fit, from panacea to practice: implementing the EU Water Framework Directive. Ecology and Society 17(3):2. https://doi.org/10.5751/ES-04821-170302

Obenour, D. R., A. D. Gronewold, C. A. Stow, and D. Scavia. 2014. Using a Bayesian hierarchical model to improve Lake Erie cyanobacteria bloom forecasts. Water Resources Research 50 (10):7847-7860. https://doi.org/10.1002/2014WR015616

Ohio Travel Association. 2015. Tourism and algal blooms: economic impact fact sheet 2015. Ohio Travel Association, Columbus, Ohio, USA. [online] URL: http://www.ohiotravel.org/ aws/OHTRV/asset_manager/get_file/108345/tourism_and_algalblooms economic impact fact sheet.pdf

Olivier, T. 2017. Institutional design and adaptation in regionalscale common-pool resource institutions: securing access to highquality drinking water in Boston, New York, Portland, and San Francisco. University of Arizona, Tucson, Arizona, USA. [online] URL: http://arizona.openrepository.com/arizona/handle/10150/625646 
Ostrom, E. 1990. Governing the commons: the evolution of institutions for collective action. Cambridge University Press, New York, New York, USA. https://doi.org/10.1017/cbo9780511807763

Ostrom, E. 2010. Polycentric systems for coping with collective action and global environmental change. Global Environmental Change 20(4):550-557. https://doi.org/10.1016/j.gloenvcha.2010.07.004

Pelosi, C., M. Goulard, and G. Balent. 2010. The spatial scale mismatch between ecological processes and agricultural management: Do difficulties come from underlying theoretical frameworks? Agriculture, Ecosystems \& Environment 139 (4):455-462. https://doi.org/10.1016/j.agee.2010.09.004

Pressey, R. L., and M. C. Bottrill. 2009. Approaches to landscapeand seascape-scale conservation planning: convergence, contrasts and challenges. Oryx 43(4):464-475. https://doi.org/10.1017/ $\underline{\mathrm{S} 0030605309990500}$

Rasmussen, L. V., C. J. Kirchhoff, and M. C. Lemos. 2017. Adaptation by stealth: climate information use in the Great Lakes region across scales. Climatic Change 140(3-4):451-465. https:// doi.org/10.1007/s10584-016-1857-0

Robins, G. 2011. Exponential random graph models for social networks. Pages 484-500 in J. Scott and P. J. Carrington, editors. Handbook of social network analysis. SAGE, Thousand Oaks, California, USA.

Robins, G., and D. Lusher. 2013. Illustrations: simulation, estimation, and goodness of fit. Pages 167-186 in D. Lusher, J. Koskinen, and G. Robins, editors. Exponential random graph models for social networks: theory, methods, and applications. Cambridge University Press, New York, New York, USA. https:// doi.org/10.1017/CBO9780511894701.015

Robins, G., P. Pattison, Y. Kalish, and D. Lusher. 2007. An introduction to exponential random graph $\left(p^{*}\right)$ models for social networks. Social Networks 29(2):173-191. https://doi.org/10.1016/ j.socnet.2006.08.002

Sabatier, P. A., W. Focht, M. Lubell, Z. Trachtenberg, A. Vedlitz, and M. Matlock. 2005. Swimming upstream: collaborative approaches to watershed management. MIT Press, Cambridge, Massachusetts, USA. https://doi.org/10.7551/mitpress/6577.001.0001

Salpeteur, M., L. Calvet-Mir, I. Diaz-Reviriego, and V. ReyesGarcía. 2017. Networking the environment: social network analysis in environmental management and local ecological knowledge studies. Ecology and Society 22(1):41. https://doi. org/10.5751/ES-08790-220141

Sayles, J. S. 2018. Effects of social-ecological scale mismatches on estuary restoration at the project and landscape level in Puget Sound, USA. Ecological Restoration 36(1):62-75. https://doi. org/10.3368/er.36.1.62

Sayles, J. S., and J. A. Baggio. 2017. Social-ecological network analysis of scale mismatches in estuary watershed restoration. Proceedings of the National Academy of Sciences 114(10):E1776E1785. https://doi.org/10.1073/pnas.1604405114

Scavia, D., J. D. Allan, K. K. Arend, S. Bartell, D. Beletsky, N. S. Bosch, S. B. Brandt, R. D. Briland, I. Daloğlu, J. V. DePinto, et al. 2014. Assessing and addressing the re-eutrophication of Lake Erie: central basin hypoxia. Journal of Great Lakes Research 40

\section{(2):226-246. https://doi.org/10.1016/j.jglr.2014.02.004}

Scavia, D., J. V. DePinto, and I. Bertani. 2016. A multi-model approach to evaluating target phosphorus loads for Lake Erie. Journal of Great Lakes Research 42(6):1139-1150. https://doi. org/10.1016/j.jglr.2016.09.007

Tengö, M., E. S. Brondizio, T. Elmqvist, P. Malmer, and M. Spierenburg. 2014. Connecting diverse knowledge systems for enhanced ecosystem governance: the multiple evidence base approach. AMBIO 43(5):579-591. https://doi.org/10.1007/ s13280-014-0501-3

U.S. Environmental Protection Agency (U.S. EPA). 2015. Lake Erie. Overviews and factsheets. U.S. EPA, Chicago, Illinois, USA. [online] URL: https://www.epa.gov/greatlakes/lake-erie

Wilson, R. S., M. A. Beetstra, J. M. Reutter, G. Hesse, K. M. DeVanna Fussell, L. T. Johnson, K. W. King, G. A. LaBarge, J. F. Martin, and C. Winslow. 2019. Commentary: achieving phosphorus reduction targets for Lake Erie. Journal of Great Lakes Research 45(1):4-11. https://doi.org/10.1016/j.jglr.2018.11.004

Wilson, R., L. Burnett, T. Ritter, B. Roe, and G. Howard. 2013. Farmers, phosphorus and water quality: a descriptive report of beliefs, attitudes and practices in the Maumee Watershed of northwest Ohio. The Ohio State University, School of Environment \& Natural Resources, Columbus, Ohio, USA.

Wyborn, C. 2015. Cross-scale linkages in connectivity conservation: adaptive governance challenges in spatially distributed networks. Environmental Policy and Governance 25 (1):1-15. https://doi.org/10.1002/eet.1657

Zhang, W., R. S. Wilson, E. Burnett, E. G. Irwin, and J. F. Martin. 2016. What motivates farmers to apply phosphorus at the "right" time? Survey evidence from the western Lake Erie Basin. Journal of Great Lakes Research 42:1343-1356. https://doi.org/10.1016/j. jglr.2016.08.007 


\section{Appendix 1.}

\begin{tabular}{ll}
\hline \hline & \multicolumn{1}{c}{ Table A1.1. Actors' Full Names } \\
\hline ID & FULL NAME \\
1 & Adams County (IN) Soil and Water Conservation District \\
2 & Allen County (IN) Soil and Water Conservation District \\
3 & Allen County (OH) Soil and Water Conservation District \\
4 & Agricultural Research Service (of USDA) \\
5 & Auglaize County Soil and Water Conservation District \\
6 & Bean/Tiffin Watershed Coalition \\
7 & Black Swamp Conservancy \\
8 & Blanchard River Watershed Partnership \\
9 & City of Defiance \\
10 & City of Findlay \\
11 & City of Toledo \\
12 & City of Ft. Wayne \\
13 & Conservation Action Project \\
15 & Defiance County Soil and Water Conservation District \\
16 & Dekalb County (IN) Soil and Water Conservation District \\
17 & Department of Environmental Quality (Michigan) \\
18 & Division of Drinking and Ground Water (Ohio) \\
19 & Division of Surface Water (Ohio) \\
20 & Farm Service Agency (USDA) \\
22 & Friends of Cedar Creek \\
23 & Fulton Soil and Water Conservation District \\
24 & Great Lakes Commission \\
25 & Great Lakes Information Network \\
26 & Great Lakes Observing System \\
30 & Hancock County Soil and Water Conservation District \\
31 & Hardin County Soil and Water Conservation District \\
32 & Heidelberg University \\
34 & Henry County Soil and Water Conservation District \\
35 & Hillsdale (MI) Conservation District \\
36 & Hoosier Riverwatch \\
37 & Indiana Department of Environmental Management \\
39 & Indiana Natural Resources Commission \\
42 & Lenawee (MI) Conservation District \\
43 & Lucas Soil and Water Conservation District \\
45 & Maumee River Basin Partnership of Local Governments \\
48 & Mercer County Soil and Water Conservation District \\
49 & Metroparks of the Toledo Area \\
&
\end{tabular}


Michigan Association of Conservation Districts

National Center for Water Quality Research -- Heidelberg

52 University

53 National Oceanic and Atmospheric Administration

$54 \quad$ Natural Resources Conservation Service

$55 \quad$ Noble County (IN) Soil and Water Conservation District

$58 \quad$ Ohio Department of Natural Resources

59 Ohio Environmental Protection Agency

60 Ohio Farm Bureau

62 Ohio Federation of Soil and Water Conservation Districts

63 Ohio Water Development Authority

65 Ohio Watershed Coordinator Blanchard

66 Ohio Watershed Coordinator Upper Maumee

82 Ottawa River Coalition

84 Paulding County Soil and Water Conservation District

85 Purdue University

86 Putnam County Soil and Water Conservation District

89 Shelby County Soil and Water Conservation District

91 St. Joseph River Watershed Initiative

92 Steuben County (IN) Soil and Water Conservation District

93 The Nature Conservancy

94 Toledo Metropolitan Area Coalition of Governments

96 University of Toledo

98 Upper Maumee Watershed Partnership

99 US Army Corps of Engineers

100 US Environmental Protection Agency

101 US Fish and Wildlife Service

102 US Geological Survey

103 Van Wert County Soil and Water Conservation District

106 Wells County (IN) Soil and Water Conservation District

107 Western Lake Erie Basin Partnership

108 Williams County Soil and Water Conservation District

109 Wood County Soil and Water Conservation District

110 Indiana Department of Natural Resources

Indiana Association of Soil and Water Conservation

112 Districts

113 Project WET (Water Education for Teachers)

114 US Department of Agriculture

115 Tri-State Watershed Alliance

116 Indiana State Department of Agriculture

117 National Association of Conservation Districts

120 National Association of State Conservation Agencies

122 National Watershed Coalition Michigan Department of Agriculture and Rural

123 Development 
124 Ohio Soil and Water Conservation Commission

125 City of Lima

128 Ohio Office of the Governor

129 Ohio General Assembly

135 Allen County

136 Auglaize County

137 Defiance County

138 Fulton County

139 Hancock County

140 Hardin County

141 Henry County

142 Lucas County

143 Mercer County

144 Paulding County

145 Putnam County

146 Shelby County

147 Van Wert County

148 Williams County

149 Wood County

150 National Corn Growers Association

152 US Forest Service

153 Ohio State University

154 City of Perrysburg

155 City of New Haven

156 City of Hillsdale

157 City of Bowling Green

158 Town of Leo-Cedarville

159 Village of Paulding

160 Ohio State University Extension

161 Ohio Water Resources Center

162 Kent State University

163 St. Marys River Watershed Project

164 Lake Erie Center

165 Adams County (IN)

166 Allen County (IN)

167 Dekalb County (IN)

168 Noble County (IN)

169 Steuben County (IN)

170 Wells County (IN)

171 Hillsdale County (MI)

172 Lenawee County (MI) 


\section{Goodness-of-fit diagnostics}

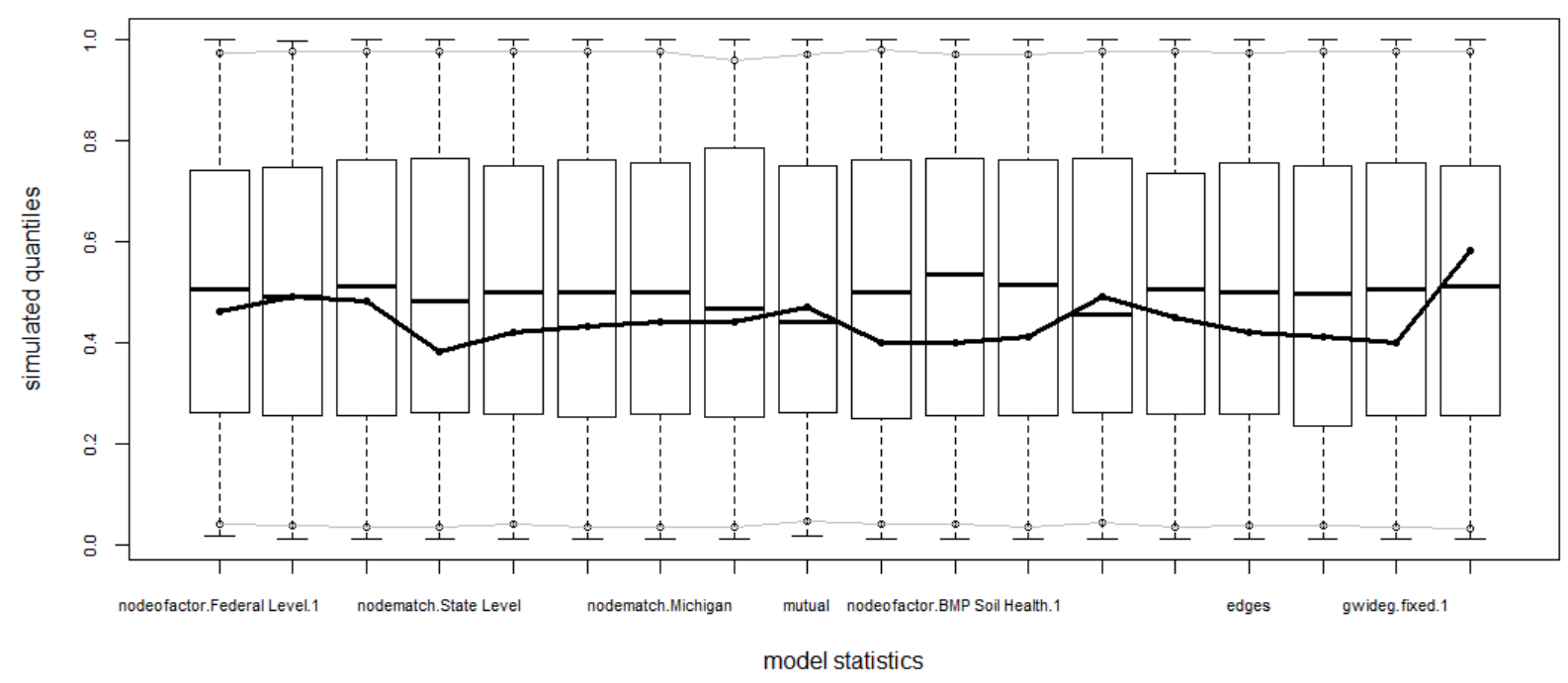

Figure A1.1. Diagnostics for Model Statistics

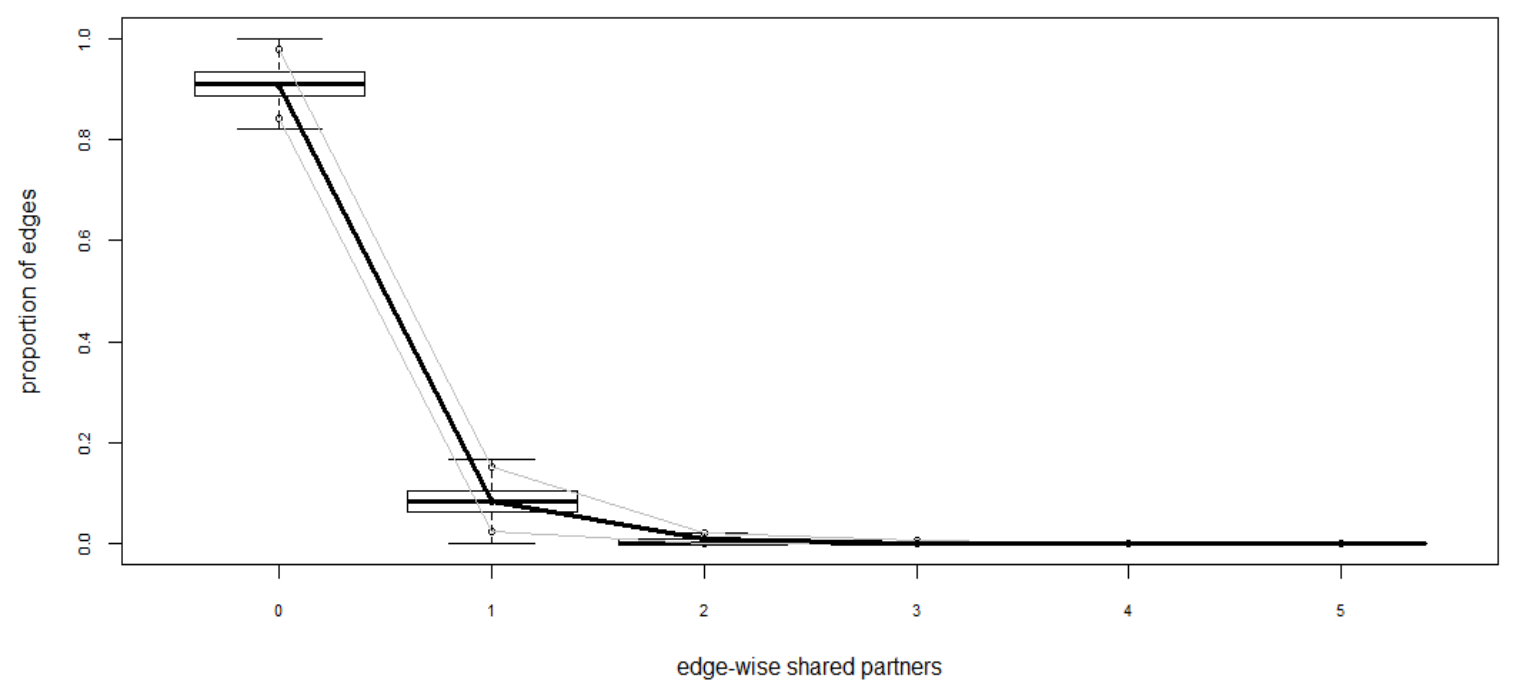

Figure A1.2 Goodness of Fit Diagnostics for Edge-Wise Shared Partners 


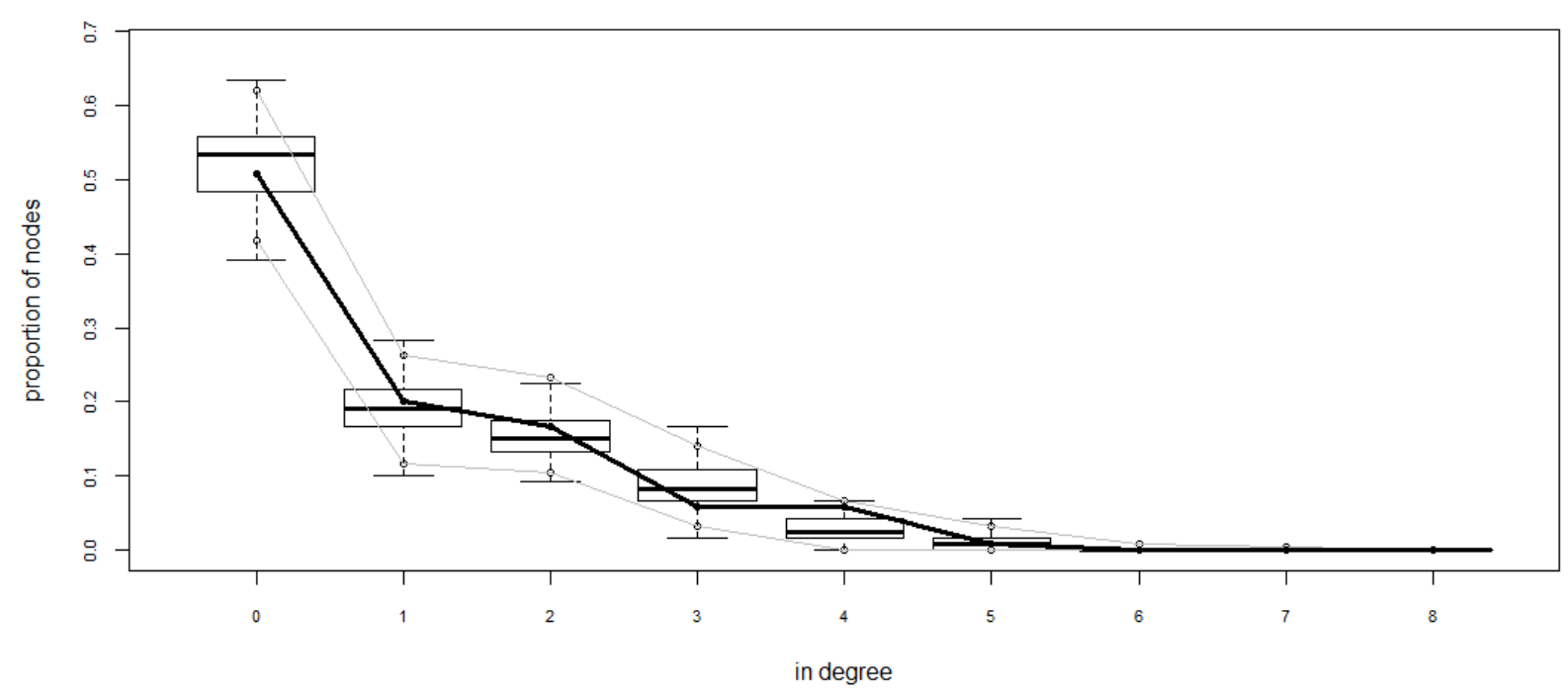

Figure A1.3. Goodness of Fit Diagnostics for Indegree Distribution

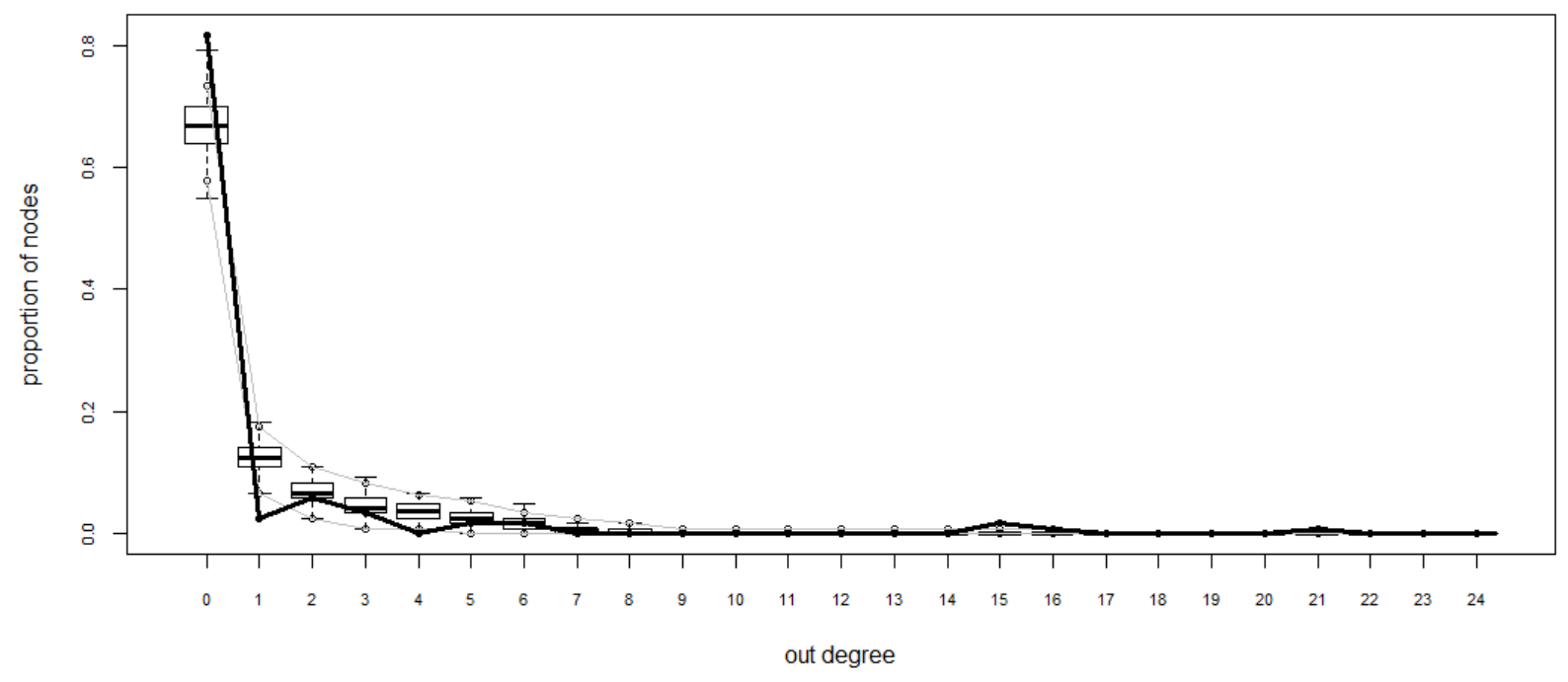

Figure A1.4. Goodness of Fit Diagnostics for Outdegree Distribution 


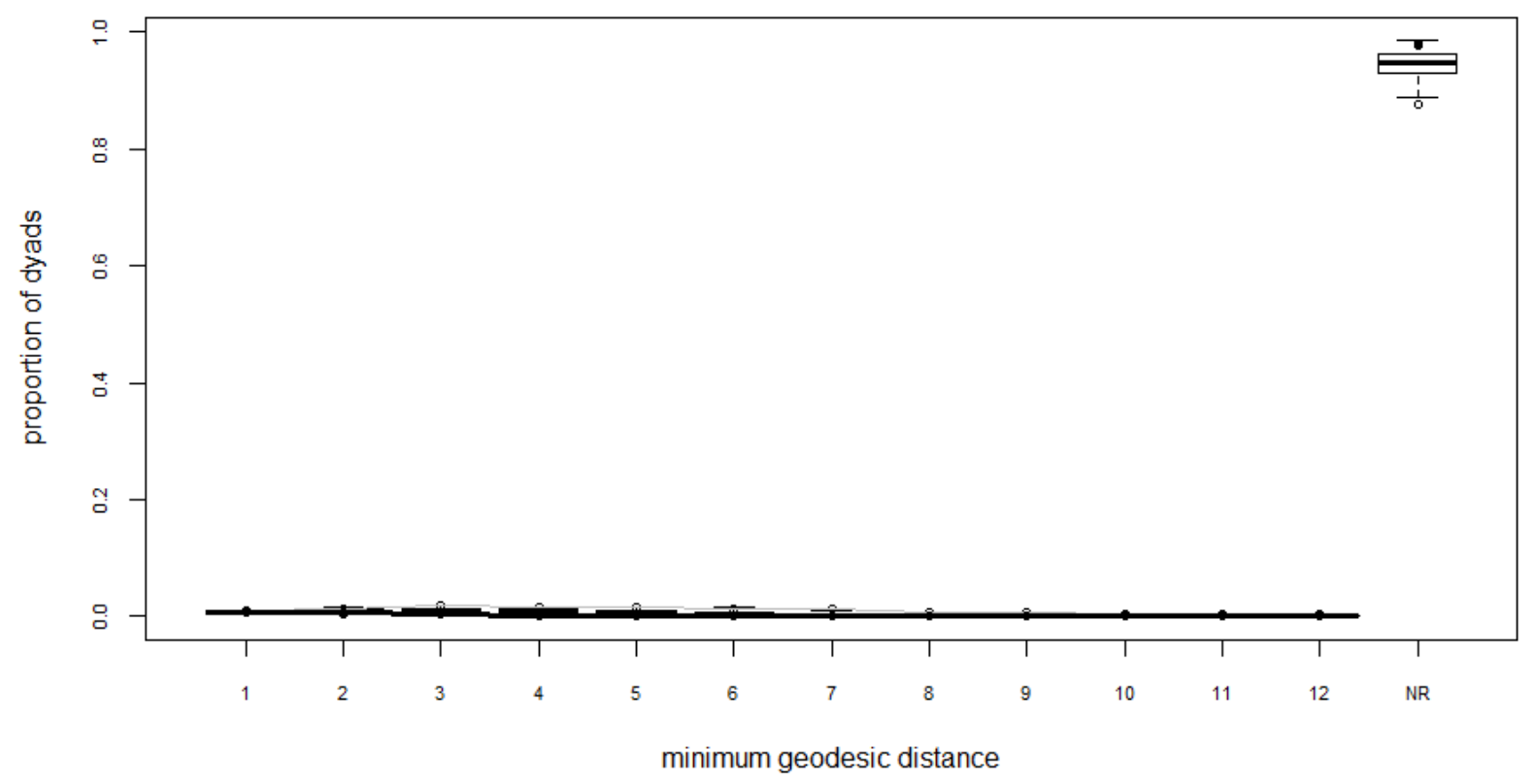

Figure A1.5. Goodness of Fit Diagnostics for Minimum Geodesic Distance 
Trace of nodeofactor.Federal Level.1

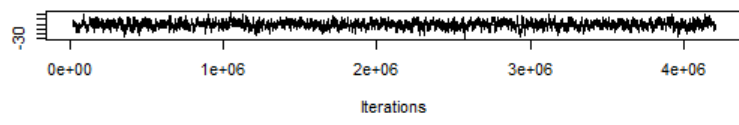

Trace of nodeofactor.State Level.1

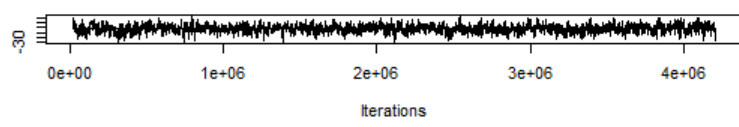

Trace of nodematch.Federal Level

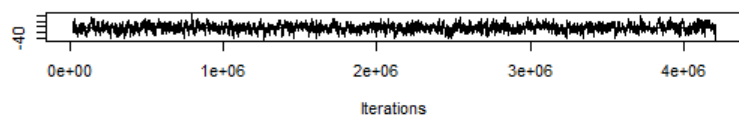

Trace of nodematch.State Level

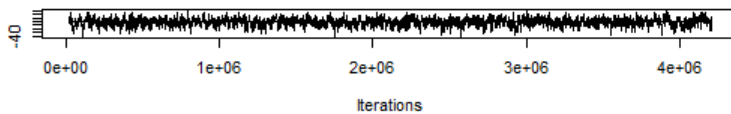

Trace of nodematch.Indiana

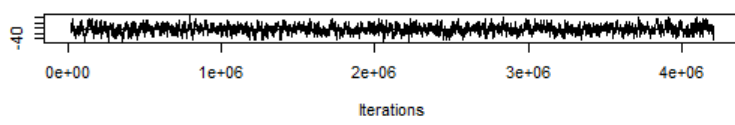

Trace of nodematch.Ohio

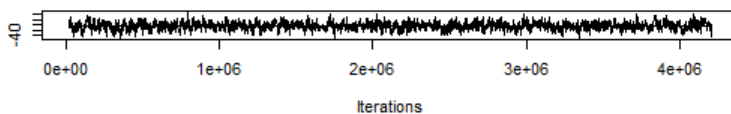

Trace of nodematch.Michigan

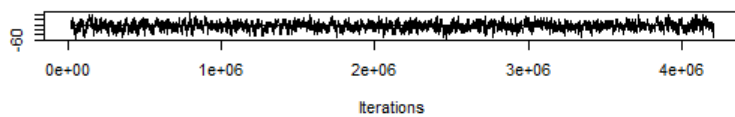

Trace of nodeofactor.Watershed Boundaries.1

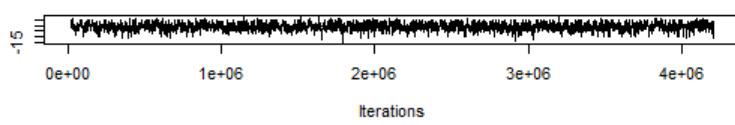

Density of nodeofactor.Federal Level.1

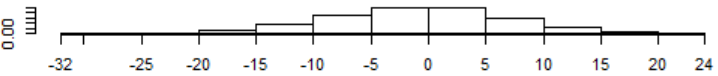

Density of nodeofactor.State Level.1

学寻

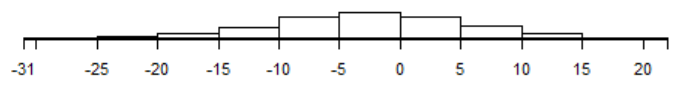

Density of nodematch.Federal Level

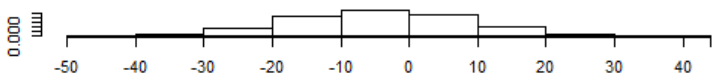

Density of nodematch.State Level

을
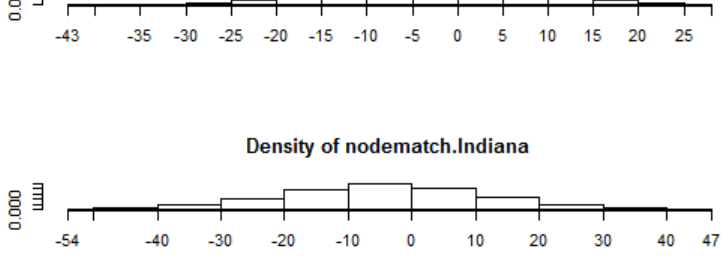

Density of nodematch.Ohio
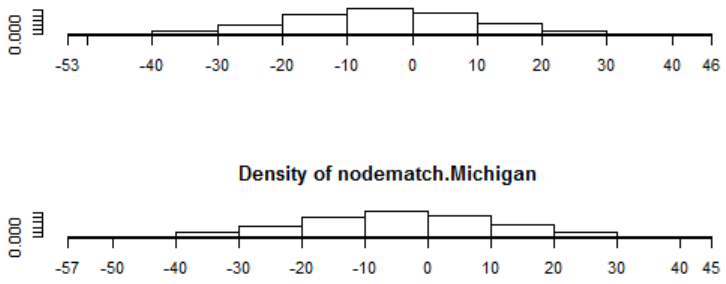

Density of nodeofactor.Watershed Boundaries.1

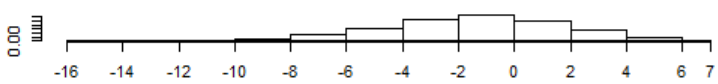


Trace of mutual

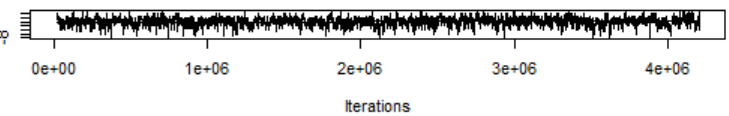

Trace of nodeofactor.BMP Nutrient.1

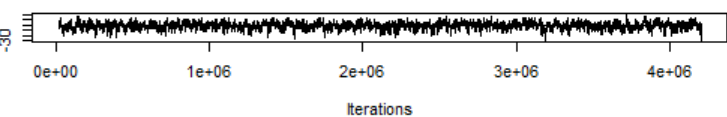

Trace of nodeofactor.BMP Soil Health.1

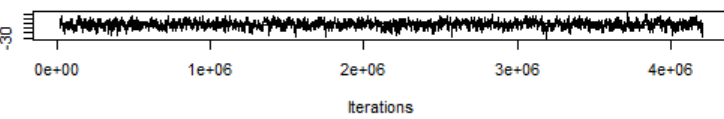

Trace of nodeofactor.BMP Water Filt.1

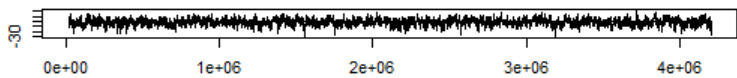

Iterations

Trace of nodeofactor.BMP Manure.1

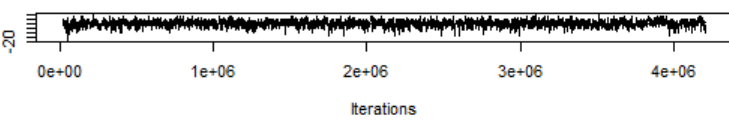

Trace of nodeofactor.Monitoring Role.1

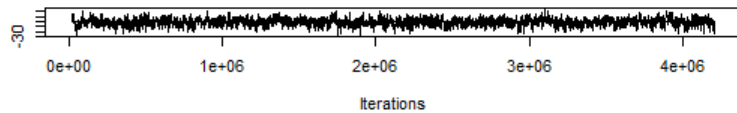

Trace of edges

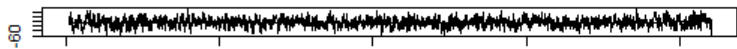
$\begin{array}{lllll}0 \mathrm{e}+00 & 1 \mathrm{e}+06 & 2 \mathrm{e}+06 & 3 \mathrm{e}+06 & 4 \mathrm{e}+06\end{array}$

Iterations

Trace of gwesp.fixed.0.5

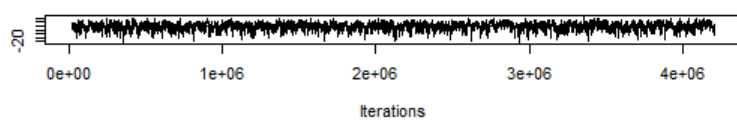

Trace of gwideg.fixed. 1

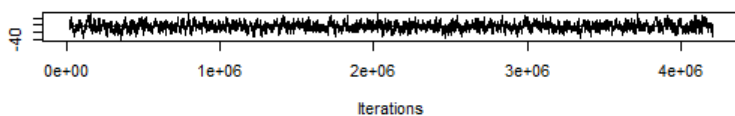

Trace of isolates

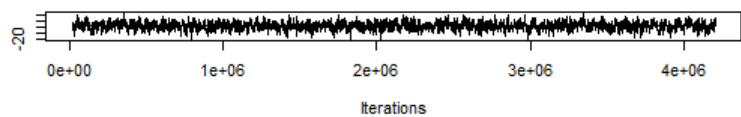

Density of mutual

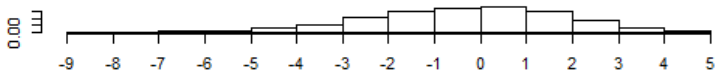

Density of nodeofactor.BMP Nutrient.1

学䒜

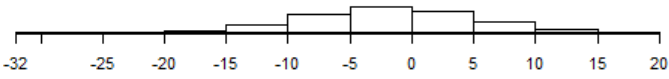

Density of nodeofactor.BMP Soil Health.1

学奉

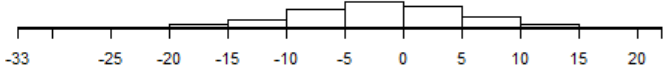

Density of nodeofactor.BMP Water Filt.1

总

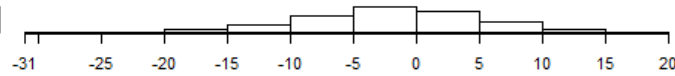

Density of nodeofactor.BMP Manure.1

学寻

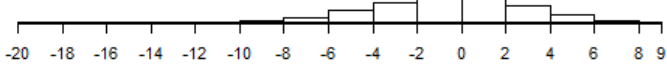

Density of nodeofactor.Monitoring Role.1

웅

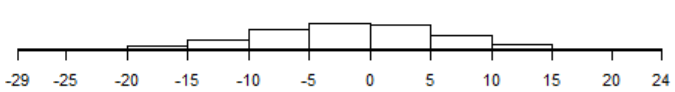

Density of edges

吅寻

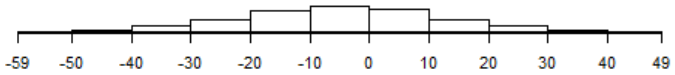

Density of gwesp.fixed. 0.5

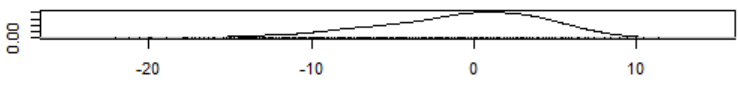

$\mathrm{N}=4096$ Bandwidth $=1.025$

Density of gwideg.fixed.1

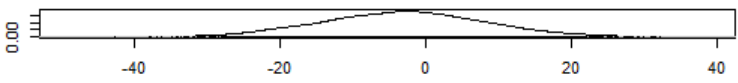

$\mathrm{N}=4096$ Bandwidth $=2.257$

Density of isolates

总寻

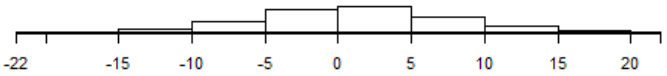

Figure A1.6. MCMC Chains for Modeled Statistics (normally distributed chains indicate proper model specification) 